together workers from different disciplines to consider three 'new frontiers' in cognitive ageing: new theoretical directions; integrations of findings from cognitive neuroscience with cognitive ageing; and the effects of biology and health on cognitive ageing.

The book will be of most interest to cognitive psychologists who specialize in memory research and want an update on some of the major findings from such methods as functional magnetic resonance imaging and positron emission tomography (PET). Those new to the field will have to go elsewhere for basic definitions of such terms as episodic and semantic memory. There is a little genetics thrown in, too - notably some brief discussions of the influence of polymorphic alleles at the apolipoprotein $\mathrm{E}$ locus on cognitive functioning and susceptibility to dementias of the Alzheimer type. We still do not know the mechanistic details of how specific alleles at this locus affect cognitive functioning even in middle age, or why these polymorphic alleles evolved and are maintained at such variable frequencies in many human populations.

We can certainly be grateful for the achievements of cognitive psychologists, epitomized by the pioneering work of Timothy Salthouse on processing speed, which is well discussed in this volume. The findings derived from joint efforts of $\operatorname{cog}$ nitive psychologists and neuroimaging experts are also nicely documented here. A striking example from a Swedish PET study is illustrated in a chapter by Lars Nyberg and Lars Bäckman, showing the altered prefrontal lateralization associated with the retrieval of certain forms of memory in normal aged human subjects compared with younger people.

What surprised me, however, was the paucity of information about recent studies on the cellular and molecular aspects of cognition and their significance for our understanding of cognitive ageing. The efforts of Ancino Silva are particularly notable: he has set up the Molecular and Cellular Cognition Society (www.molcellcog.org), which meets in connection with the annual meeting of the Society for Neuroscience, a cosy little gathering of almost 30,000 neurobiologists.

The cover image of this book, a painting by Zbigniew Pronaszko shown on the previous page, reminded me that depressive illness is very common in older people and may sometimes be misdiagnosed as an early form of dementia.

George M. Martin is emeritus director of the Alzheimer's Disease Research Center, University of Washington, Seattle, Washington 98195, USA.

\section{More on ageing}

\section{Forever Young: A Cultural History of Longevity}

by Lucian Boia

Reaktion, 224 pp. £16.95, \$25

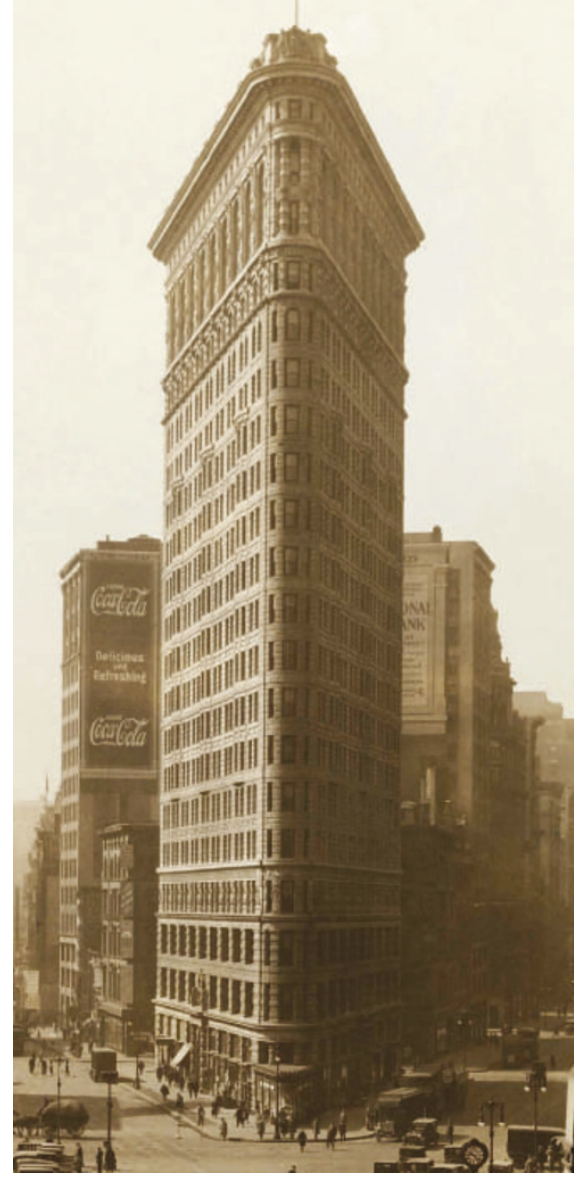

Is it a cave? The Flatiron Building in New York was the tallest skyscraper of its day.

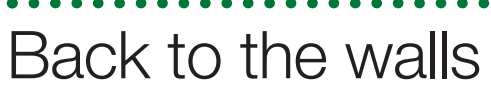

\section{The Urban Cliff Revolution: New Findings on the Origins and Evolution of Human Habitats} by Douglas Larson, Uta Matthes,

Peter E. Kelly, Jeremy Lundholm \&

John Gerrath

Fitzhenry \& Whiteside: 2004. 272 pp. $\$ 28.95$

\section{Clive Gamble}

In uncertain times, where do we feel safest? The answer usually involves strong walls, whether they are part of a castle keep, a nuclear shelter or a panic room. We also feel that there is safety in numbers, thanks to combined strength and abundant lookouts, and in remote places, such as desert islands. But these are all short-term views. When asked by evolutionary ecologists, the question becomes: would we be better off up a tree in a tropical rainforest, out on the savannah or lurking in reed beds around a lake? The answer must take into account our evolutionary history and consider how security contributed to the radiation into so many different fossil species. It also needs to ask whether our current psychological response to different places, in terms of where we feel safe, can be traced to our evolutionary past.

A wide range of evolutionary disciplines, including archaeology, palaeoanthropology, psychology, biology, molecular genetics and quaternary science, have tried to find answers to this question, which often leads to a search for the original environmental setting to help explain our present condition. The search is expressed in many ways but tends to encompass the garden of Eden, cradles of human civilization, evolutionary adaptation and E. O. Wilson's biophilia, the biological basis of attraction.

Ecologists add another factor in this engagingly written book. The 'urban cliff' hypothesis argues for the importance of cliffs and other rocky outcrops for a very productive group of species: humans and our commensals and mutualists. Out of these rocky habitats, which account for less than $1 \%$ of the Earth's vegetation-covered surface, come an astonishing array of plant and animal species that we have removed from these ecologically poor refuges. These pets, pests and food items are indicative for the authors of the importance of a rock-walled paradise in human evolution. To demonstrate this, they rehabilitate the caveman into a cliff-dweller and give him a mission: to recreate the ancestral home not as an urban jungle but as concrete city canyons.

Sometimes the authors' enthusiasm for their hypothesis carries them away. Their photographs liken the steps of the Capitol building in Washington to the slope in front of a cave, and a gallery in the Metropolitan Museum of Art in New York represents a modern-day version of an art-filled cave. They suggest that we are deeply attracted to cliffs because they once provided places of safety. Our liking for tower blocks stems from a residual biological memory.

But if there is a habitat comparable to the modern city, it is surely the tree tops. High above our city streets is a place of safety where a well adapted superhero such as Spiderman can put aside his psychological traumas and patrol the unsafe streets below. By comparison, the Batcave is nothing more than a glorified garage. Rock shelters, in my experience, are great if you have forgotten your tent. They retain heat in the back wall like a night storage radiator — but beware of falling rocks.

The urban cliff hypothesis is another way of saying that humans are involved in niche construction. But there never was a rockwalled paradise with good homeland security against prowling predators. Humans act on the environment just as it acts on us. The 'natural' landscape does not exist today and never has. Our psychological response to the modern world does not depend on where we went for an untroubled night's sleep a few hundred thousand years ago.

Clive Gamble is professor of geography at Royal Holloway, University of London, Egham, Surrey TW20 OEX, UK, and co-director of the British Academy Centenary Project, Lucy to Language: the Archaeology of the Social Brain. 